\title{
Molecular defects in thyroid dysgenesis
}

\section{Catia Mio ${ }^{1}$ @ | Giorgio Grani ${ }^{2}$ (1) | Cosimo Durante ${ }^{2}$ | Giuseppe Damante ${ }^{1,3}$}

\author{
${ }^{1}$ Department of Medicine, University of Udine, \\ Udine, Italy \\ ${ }^{2}$ Department of Translational and Precision \\ Medicine, Sapienza University of Rome, Rome, \\ Italy \\ ${ }^{3}$ Institute of Medical Genetics, Academic \\ Hospital "Azienda Sanitaria Universitaria \\ Integrata di Udine", Udine, Italy

\section{Correspondence} \\ Dr. Catia Mio, Department of Medicine, \\ University of Udine, Piazzale Kolbe 4, 33100 \\ Udine, Italy. \\ Email: catia.mio@uniud.it
}

\begin{abstract}
Congenital hypothyroidism $(\mathrm{CH})$ is a neonatal endocrine disorder that might occur as itself or be associated to congenital extra-thyroidal defects. About $85 \%$ of affected subjects experience thyroid dysgenesis (TD), characterized by defect in thyroid gland development. In vivo experiments on null mice paved the way for the identification of genes involved thyroid morphogenesis and development, whose mutation has been strongly associated to TD. Most of them are thyroid-specific transcription factors expressed during early thyroid development. Despite the arduous effort in unraveling the genetics of TD in animal models, up to now these data have been discontinuously confirmed in humans and only $5 \%$ of TD have associated with known null mice-related mutations (mainly PAX8 and TSHR). Notwithstanding, the advance in genetic testing represented by the next-generation sequencing (NGS) approach is steadily increasing the list of genes whose highly penetrant mutation predisposes to TD. In this review we intend to outline the molecular bases of TD, summarizing the current knowledge on thyroid development in both mice and humans and delineating the genetic features of its monogenetic forms. We will also highlight current strategies to enhance the insight into the non-Mendelian mechanisms of abnormal thyroid development.
\end{abstract}

\section{KEYWORDS}

congenital hypothyroidism, thyroid dysgenesis, next-generation sequencing, null mice

\section{1 | INTRODUCTION}

Congenital hypothyroidism $(\mathrm{CH})$ is one of the most prevalent neonatal endocrine disorders, with a global incidence of 1:2000 to 1:4000 worldwide. ${ }^{1} \mathrm{CH}$ could occur as an isolated condition, but could also be associated to congenital extra-thyroidal malformation. ${ }^{2} \mathrm{CH}$ needs to be treated within very few weeks after birth to avoid a reduction in mental functions development and the occurrence of irreversible intellectual disability. ${ }^{3}$ Thus, neonatal screening have been implemented to early identify newborn affected by $\mathrm{CH}$ : this ensures a suitable replacement therapy and a proper development of central nervous system. ${ }^{4}$ The pathogenetic events associated to $\mathrm{CH}$ could be grouped into two major classes: (a) thyroid dysgenesis (TD) (about $85 \%$ of $\mathrm{CH}$ ), characterized by defect in thyroid gland development, and (b) dyshormonogenesis, which results from inborn errors in thyroid hormone synthesis. ${ }^{5} \mathrm{CH}$ caused by TD occurs with an incidence of about 1:3000 newborns and could consist in either (1) thyroid athyreosis, hemiagenesis, hypoplasia (total or partial absence of thyroid tissue), or in (2) ectopic thyroid gland. ${ }^{6-8}$ About $25 \%$ of $\mathrm{CH}$ cases experience the total or partial absence of thyroid tissue, which is mainly caused by defects of follicular cells differentiation during the embryogenesis. Thyroid gland ectopy (about 75\% of $\mathrm{CH}$ cases), instead, is due to a migration defect of thyrocyte precursors from their endodermal origin (ie, in the midline of the pharyngeal floor just behind the prospective tongue) to the final thyroid location. ${ }^{9}$ The absence of thyroid tissue and the gland ectopy are distinct morphological entities that, however, represent variants of the same developmental aberration. ${ }^{10,11}$ 
The adult thyroid originates from two distinct precursors: endodermal cells of the primitive pharynx, which give rise to the thyroid follicular cells (TFC), and neural crest cells (migrated into the bilateral ultimobranchial body during early development) that will generate the parafollicular C cells. In the endodermal cells located in the primitive pharynx, thyrocyte determination (ie, the very beginning of the TFC developmental program) occurs at E8-8.5 and E20-22 in mouse and humans, respectively, completing the downward migration at E13.5 and E45-50 (Figure 1). Indeed, the fusion with the ultimobranchial bodies and the appearance of follicular structures occurs at E14-15.5 in mouse and in E60-70 in humans. ${ }^{12}$

Because TD concordance between monozygotic twins is extremely low, ${ }^{13,14}$ it would indicate that monogenic germline mutations are not a frequent cause of TD. Accordingly, putative causative mutations have been only highlighted in about $10 \%$ of TD-affected subjects. ${ }^{15}$ Moreover, only $2 \%$ of TD subjects has an affected relative. Because of this scenario, it has been hypothesized that the majority of TD cases results from either epigenetic abnormalities, early somatic mutations, or postzygotic stochastic events. ${ }^{12,13}$ However, to date, data supporting these hypotheses are still scarce. In contrast, the list of genes whose highly penetrant mutation predisposes to TD is steadily increasing.

This review will focus on the molecular bases of TD, summarizing the current knowledge on thyroid development in both mice and humans and outlining the genetic features of its monogenetic forms and highlighting current research strategies to enhance the insight into the non-Mendelian mechanisms of abnormal thyroid development.

\section{ANIMAL MODELS OF THYROID DYSGENESIS}

Undoubtedly, knockout mice provided initial evidences that gene function abolition of several tissue-specific transcription factors indeed disrupts thyroid development and, therefore, can be associated to human TD. Notably, researchers' attention focused on those tissue-specific transcription factors (tsTFs) that were expressed during early thyroid development.

\section{1 | HOXA3}

The Hoxa3 gene is Hox paralog that is expressed in both the neural crest-derived mesenchymal cells of the pharyngeal arches and in the pharyngeal endoderm. ${ }^{16}$ Hoxa3-deficient mice showed thymus and thyroid hypoplasia, this latter due to a reduced number of both endoderm-derived follicular cells and neural crest-derived parafollicular cells.

\section{2 | NKX2-1}

The first gene encoding for a tsTF fostering thyroid-specific gene expression was NKX2-1 (also called TTF-1, TITF1 or T-EBP). ${ }^{17}$ The encoded protein interacts with specific DNA sequences through a homeodomain ${ }^{18}$ and, to date, several gene promoters targeted by this TF are known. ${ }^{19,20}$ Transgenic mouse models indicate that Nkx2-1, sonic hedgehog (Shh), as well as Hes1 play a role for correct symmetrical lobulation of the median thyroid anlage. ${ }^{21}$ NKX2-1 plays a major role in the regulation of key genes involved in thyroid differentiation (ie, TSHR, TG and TPO). During development, NKX2-1 is expressed in the primordia of thyroid, lung and several areas of central nervous system. ${ }^{17,22}$ In addition to lung and forebrain abnormalities, the Nkx2-1 -/- mouse exhibits a visible embryonic thyroid bud which disappears around E10.5-11, but normal parathyroid glands. ${ }^{23}$

\section{3 | PAX8}

Pax8 is a member of the PAX protein family and binds DNA through the paired domain. ${ }^{24}$ This protein is expressed during thyroid, kidney and midbrain-hindbrain boundary development. ${ }^{25}$ The Gruss group showed that Pax8 ${ }^{-1-}$ mice developed smaller thyroid glands with absence of follicles, concluding that the aberration creates a defect in competent endoderm primordia differentiation into thyroxinproducing follicular cells. ${ }^{26}$ Additionally, the disappearance of the thyroid cell precursors in Pax $8^{-1-}$ mice at about E11-11.5 suggest a putative role for PAX8 in thyroid precursor cell survival. ${ }^{27}$

\section{$2.4 \mid$ FOXE1}

The FOXE1 gene (named also TTF2) encodes for a forkhead domain transcription factor whose expression is present in the developing thyroid, in most of the foregut endoderm and in the craniopharyngeal ectoderm that will give rise to the anterior pituitary gland. ${ }^{28}$ Foxe $1^{-/-}$ mice showed cleft palate and either a sublingual or completely absent thyroid gland. ${ }^{11}$ Therefore, this was the first evidence indicating that thyroid ectopy can arise due to loss-of-function mutations of a thyroid-specific transcription factor.

\section{5 | HHEX}

The transcription factor HHEX interacts with specific DNA sequences through a divergent homeodomain. ${ }^{29}$ During early mouse development, this homeobox gene is expressed in the anterior visceral endoderm and rostral definitive endoderm. At later stages, Hhex is expressed in liver, thyroid and endothelial precursor cells. ${ }^{30}$ Various data indicated that this protein contributes to molecular events related to thyroid gland differentiation. ${ }^{31,32}$ Besides many other defects, hhex ${ }^{-1-}$ embryos exhibit the arrest of thyroid development at the budding stage (E9.5). ${ }^{33}$ However, it has been shown that Hex is not required for specification of thyrocyte precursors, as demonstrated by the normal onset of Titf1, Pax8, and Foxe1 gene expression in the absence of Hhex. Conversely, later in the developmental stages, a large decrease in the number of thyroid cell precursors and a regression in the morphology of the developing gland are detected in absence of hhex expression. Thus, it appears that Hhex plays a chief role in cell proliferation. ${ }^{34}$ 


\section{6 | HES1}

Besides to act in the control of thyroid development, the transcription factors NKX2-1, PAX8, FOXE1 and HHEX transactivate promoters of genes with a thyroid specific expression such as TG, TPO and NIS. ${ }^{19} \mathrm{~A}$ similar behavior was highlighted in the basic Helix-Loop-Helix protein HES1. In fact, this protein is able to transactivate both NIS promoter ${ }^{35}$ and control thyrocyte and C-cells precursors. Hes1-/- mice show thyroid hypoplasia and a decreased T4 and calcitonin immunohistochemical positivity. ${ }^{36}$ Indeed, HES1 is regulated by the NOTCH pathway, ${ }^{37}$ a highly conserved cell-to-cell communication system involved in the specification of many tissues, that is, several foregutderived endocrine ones. Notch plays an essential role during the earlier phases of thyroid primordium induction. In fact, Notch directs Hes1 expression regulating its inhibitor, the recombining binding protein suppressor of hairless RBPJ. ${ }^{38}$ The manipulation of this signaling pathway in zebrafish allowed to associate a Notch-Hes1 axis disruption to thyroid dysgenesis. ${ }^{39}$

\section{7 | EYA1}

Targeted inactivation of Eya1 impaired early developmental processes in multiple organs. ${ }^{40}$ It has been shown that Eya1 ${ }^{-/-}$mice had hypoplastic thyroid lobes (40\%-60\% decrease in volume), lack of isthmus and reduction of calcitonin-producing cells; although follicles were present, the number of follicular cells was reduced. ${ }^{41}$ In the same experimental setting, no Eya1 expression was observed during thyroid gland development, suggesting the possibility that the effects on mature gland are ancillary.

\section{8 | TSHR}

In addition to transcription factors deficiency, TD can be observed in animal models in which the function of the thyroid-stimulating hormone receptor (TSHR) gene is reduced. Activation of the TSHR by TSH pathway occurs at E15 in mice, much later than the beginning of thyroid development. According to this, mice with either naturally occurring TSHR mutation or knockout show a normal thyroid gland at birth but reduced weight few weeks later. ${ }^{42,43}$ These data lead to the conclusion that activation of TSHR does not have a relevant effect on thyrocyte proliferation during development but it is necessary for the maintenance of the thyroid gland size and structure postnatally. By using the CRISPR/CAS9 system, loss of function mutations have been recently introduced in the rat TSHR gene. ${ }^{44}$ At 8 weeks after birth, TSHR homozygous mutant rats showed a hypoplastic thyroid associated to a marked decrease in the number of both thyroid follicular cells and parafollicular cells.

\section{$2.9 \mid$ TUBB1}

In order to find the role of TUBB1 gene mutations found in TD patients, the null mouse model was recently generated. ${ }^{45}$ TUBB1 encodes for tubulin beta 1 , class $\mathrm{VI}$, a protein of the $\beta$-tubulin family, which is incorporated into microtubules as $\alpha / \beta$ dimers. This gene is expressed in the thyroid (during development and adulthood), mega-

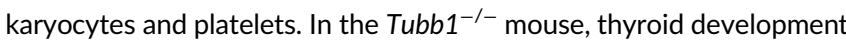
was deranged in a complex way: at early stage (E9.5) the surface area of the thyroid anlage was bigger than in normal mice; at E11.5 delayed migration of the gland was observed and at E13.5 significant hypoplasia was detected.

\subsection{0 | The polygenic model}

Knockout experiments provided evidence for a putative polygenic cause underling TD. In fact, while Titf1 ${ }^{+/-}$and Pax ${ }^{+/-}$mice displayed no alteration in thyroid development, [Titf1, Pax8 ${ }^{+/-}$mice showed smaller thyroid glands or hemiagenesis. Moreover, it was demonstrated that the abnormal thyroid phenotype is strain specific and that variation of at least two other genes is required. ${ }^{46}$ Furthermore, the same lab identified the Dnajc17 gene, which encodes for a member of the type III heat-shock protein-40 family, as one of the genes whose mutations are required to induce TD in [Titf1, Pax8 ${ }^{+/-}$ mice. ${ }^{47}$

\section{3 | MOLECULAR DEFECTS ASSOCIATED TO TD IN HUMANS}

Studies on the molecular basis of TD in the pre-next-generation sequencing (NGS) era were usually focused on a limited number of genes and/or a small number of cases. Causative mutations were identified in less than $5 \%$ of TD cases, leading to the assumption that TD is a sporadic disease. Monogenic loss-of-function mutations in NKX2-1, PAX8, TSHR and FOXE1 are rare but well-established causes of TD; however, expressivity and phenotypic penetrance may be highly variable even within the same family.

The advent of NGS, which allowed the simultaneous and systematic analysis of known candidate genes (targeted NGS) or of the entire exome (whole-exome sequencing, WES) made the research on TD more efficient and recently opened novel perspectives on the pathogenesis of TD, that are consistent with both some previous findings obtained in animal models and the variable expression and penetrance of genetic defects within families.

\section{$3.1 \mid \mathrm{NKX} 2-1$}

NKX2-1 mutations are associated to the "brain-lung-thyroid" syndrome, a triad characterized by various combinations of TD, infant respiratory distress syndrome (IRDS), and benign hereditary chorea (BHC). Hypothyroidism is usually mild or subclinical with thyroid hypoplasia, haemiagenesis or athyreosis. ${ }^{48}$ Moreover, deletions proximal to NKX2-1 have also been implicated, suggesting the presence of an upstream enhancer in this region. ${ }^{49}$ Concerning the thyroidal abnormalities, a predominance of normal thyroid-in-situ over TD (hypoplasia or hemiagenesis, 35\%-50\%; athyreosis, 10\%) was reported. ${ }^{15}$ Only one case with NKX2-1 mutation with a thyroid 
ectopy has been reported so far. NKX2-1 mutations may exhibit autosomal dominant inheritance with variable expressivity and penetrance, but frequently occur de novo. ${ }^{48,49}$ General mutational screening in three non-syndromic TD cohorts detected no NKX2-1 mutations. ${ }^{27,50}$

\section{2 | PAX8}

To date,29 heterozygous loss-of-function PAX8 alterations, the majority comprising substitutions affecting the DNA-binding domain, are reported as disease causing, transmitted among familial cases via an autosomal dominant pattern of inheritance with incomplete penetrance and variable expressivity. ${ }^{51}$ Affected patients predominantly exhibit thyroid hypoplasia. However, ectopy and athyreosis, albeit rare, might also occur. From a biochemical point of view, euthyroidism to severe hypothyroidism have been described, and thyroid gland morphology ranges from a normal-sized gland to apparent athyreosis. $^{52}$

\section{3 | FOXE1}

Homozygous mutations in FOXE1 were reported in patients with a syndromic form of TD, the Bamforth-Lazarus syndrome, characterized by TD (ie, athyreosis or severe hypoplasia), cleft palate, and spiky hair. To date, at least eight biallelic TD-associated FOXE1 point mutations have now been reported. ${ }^{27}$ Inheritance of FOXE1 mutations is autosomal recessive and all described mutations cluster in the forkhead DNA-binding domain. Carrè et al, performing a case-control association study (affected $N=115$, controls $N=129$ ), concluded that FOXE1 through its alanine containing stretch modulates significantly the risk of TD occurrence, declassifying FOXE1 as a susceptibility gene for TD rather than a disease-causing gene. ${ }^{53}$

\section{4 | TSHR}

In humans, about 113 loss-of-function (LOF) mutations in the TSHR gene have been reported in the Human Gene Mutation Database HGMD (HGMD Professional 2019.1) in association with various degrees of TSH resistance. The spectrum of associated phenotypes ranges from euthyroid hyperthyrotropinemia (ie, elevated TSH with free-T4 in the normal range) to $\mathrm{CH}$ with an orthotopic but hypoplastic gland. ${ }^{51}$ The extent of TSH resistance is tightly correlated to the zygosity of the mutation (ie, homo- or heterozygous mutation) and on the type of functional impairment at protein level. Recessively inherited TSHR homozygous mutations are associated with complete lack of the receptor's function and orthotopic thyroid hypoplasia. Heterozygous mutations, instead, usually following an autosomal dominant inheritance, have been reported in patients with nonautoimmune subclinical hypothyroidism associated to a normal sized orthotopic gland. ${ }^{51,54}$ Heterozygous loss-of-function TSHR mutations are most frequently described, with incidences of $10 \%$ to $30 \%$ in an Italian cohort of hyperthyrotropinaemia-affected subjects. ${ }^{55}$ Notwithstanding, the main feature of TSHR mutations is the high level of phenotypic variability wherein the same mutation can be associated with different levels of thyroid function.

Indeed, TSHR mutations occur throughout the protein sequence, with nonsense and frameshift mutations generally decreasing TSHR levels through the plasma membrane, but also affecting ligand binding, depending on their location. ${ }^{54}$ In a scenario of complete TSH resistance with subnormal free-T4 levels, levothyroxine replacement is unequivocally required. TSHR mutations are known to cause partial TSH resistance. In this context, hormonal replacement remains controversial because elevated TSH levels are sufficient to maintain normal circulating thyroid hormone concentrations. ${ }^{27,54,56}$

\section{5 | GLIS3}

GLIS3 is a member of the GLI-similar 1 to 3 (GLIS1-3) subfamily of Krüppel-like zinc finger protein transcription factors, encoding for a nuclear protein potentially acting as downstream modulator of sonic hedgehog pathway and known to play a main role in regulating embryogenesis. ${ }^{27}$ Biallelic loss-of-function mutations in GLIS3 have been described in different families and are robustly associated with TD. Inheritance is autosomal recessive. Thyroid involvement in GLIS3mutated patients include thyroid aplasia, diminished colloid with interstitial fibrosis, and apparently normal thyroid texture on ultrasound, but with temporary TSH resistance upon thyroxine treatment, perhaps explained by its actions downstream of TSH and the TSHR, because GLIS3 is indispensable for TSH/TSHR-mediated proliferation of thyroid follicular cells and biosynthesis of thyroid hormone. ${ }^{15,57}$

\section{6 | JAG1}

Jagged1, encoded by the JAG1 gene, is a Notch receptor ligand expressed in thyroid, which may play a role in thyroid specification in zebrafish, as well as in differentiation and maintenance of thyroid precursor cells. ${ }^{39,58}$ Human heterozygous loss-of-function JAG1 mutations are associated with Alagille syndrome type 1 (ALGS1), which is characterized by variable involvement of liver, heart, skeleton, eye and facial defects. Evaluation of thyroid function in 21 cases with Alagille syndrome showed that variations in JAG1 gene can contribute to the pathogenesis of variable congenital thyroid defects, including TD. ${ }^{59}$

\section{7 | CDCA8}

Borealin, encoded by the CDCA8 gene, is a member of the chromosomal passenger complex with roles in the processes of chromosome segregation and cytokinesis. It is expressed in human thyroid tissue during embryonic development and in vitro transfection of mutant CDCA8 resulted in altered cellular migration and adhesion through the decrease in the expression of focal adhesion-related genes. ${ }^{60} \mathrm{~A}$ recent WES approach on familial cases with TD allowed to highlight biallelic mutations of CDCA8 in two cases of one consanguineous family, and monoallelic mutations in two other sporadic cases. ${ }^{27,51}$ 


\section{8 | NKX2-5}

NKX2-5 belongs to the NK-2 family of homeodomain-containing transcription factors; it was initially an attractive candidate gene for TD, bevause murine Nkx2-5 -/- embryos exhibit thyroid bud hypoplasia, thus, suggesting that Nkx2-5 signal contributes the organogenesis of the thyroid. ${ }^{61}$ However, despite an initial report of four patients with heterozygous loss-of-function NKX2-5 mutations and thyroid ectopy or athyreosis, the role of NKX2-5 in TD remains ambiguous. ${ }^{27}$ The penetrance of the identified mutations turned to be highly variable and pathogenic mutations showed to also occur in healthy populations. These data led clinicians to suggest that NKX2-5 mutations do not represent a major contributor in TD pathogenesis.

\section{9 | NTN1}

In a single patient a heterozygous deletion involving part of NTN1 was detected, whose phenotype involved congenital ventricular septum defect (VSD) and thyroid ectopy. Functional studies in zebrafish showed that $n t n 1 a$ is expressed in pharyngeal arch mesenchyme but not in thyroid tissue. Indeed, it is likely that the detected TD is due to the lack of guidance cues from the dysplastic vasculature more than a thyroid specific defect. ${ }^{62}$ To date, it is unclear in which the NTN1 mutations contribute to the shared thyroid and cardiac congenital defects within the population.

\subsection{0 | TUBB1}

In a recent paper Stoupa et al identified three different TUBB1 mutations strongly associated to TD. ${ }^{45}$ Within the same family, two patients presented thyroid gland ectopia and macroplatelets, phenotype associated to a homozygous TUBB1 loss-of-function mutation. Moreover, in a cohort of 270 TD patients, they demonstrated that $1.1 \%$ of subjects possessed a loss-of-function mutation in TUBB1 associated to a variable thyroid phenotype ranging from gland ectopia to mild thyroid asymmetry, thyroid hypoplasia and hemithyroid. ${ }^{45}$ The variability of the phenotype, even within the same familial cluster, could be explained the hypothesis of random autosomal monoallelic gene expression in the thyroid, that is, the transcription of a gene from one of two homologous alleles. ${ }^{6,63,64}$

\subsection{1 | THRB}

A paper by Zhou et al highlighted two THRB missense mutations screening a cohort of 280 patients with TD and 200 normal subjects. ${ }^{65}$ The thyroid hormone receptor $\beta$ (THRB), indeed, possesses a ligand-binding domain (LBD) in the $\mathrm{C}$-terminus through which it interacts with the T3 thyroid hormone. Patients harboring THRB mutations develops TD, with or without an ectopic lingual thyroid. ${ }^{65,66}$ Functional characterization the THRB C36Y mutation revealed changes in cell morphology that inhibited the human thyroid cell line Nthy-ori 3-1 proliferation, promoting apoptosis. ${ }^{65}$

\subsection{2 | Syndromic TD}

It is already known that TD risk is increased in the context of several syndromes with an underlying genetic basis and predominantly extrathyroidal-related abnormalities. The most common forms of syndromic hypothyroidism include Pendred syndrome (SLC26A4), Bamforth-Lazarus syndrome (FOXE1), the brain-lung-thyroid syndrome (NKX2-1) and the Alagille syndrome type 1 (JAG1). Notwithstanding, ongoing genetic research continues to shed new light on some candidate genes involved in syndromic TD, such as SALL1 (Townes-Brocks syndrome), TBX1 (di George syndrome), URB1 (Johanson-Blizzard syndrome), DYRK1A (Down syndrome), ELN and BAZ1B (Williams-Beuren syndrome), KMT2D and KDM6A (Kabuki syndrome), KAT6B (Ohdo syndrome, Genitopatelar syndrome). ${ }^{27,67,68}$ Moreover, other syndromic forms involving thyroid abnormalities exist, in which the underling genetic alteration is still missing. One clear example is the so-called PHACE syndrome, a complex congenital disorder associated to central hypothyroidism and thyroid dysgenesis. ${ }^{69}$

In all the aforementioned conditions, the underlying mechanisms for TD is so far unknown. As such, TD represents one of the remaining enigmas in the pathophysiology of thyroid diseases.

\section{4 | DISCUSSION}

Over the past decades, research conducted primarily by the Roberto Di Lauro's lab ${ }^{12,17,18,22,28,34,70}$ lead to the identification of NKX2-1, PAX8 and FOXE1 as key developmental genes involved in the regulation of the expression of thyroid-specific genes and in embryonic development of the thyroid anlagen (Figure 1).

The animal models described so far demonstrated that mutations in a group of genes tightly involved in thyroid morphogenesis cause defects in thyroid development underlying TD. Despite the arduous effort in unraveling the genetics of TD in animal models, up to now data obtained in animal models have been discontinuously confirmed in humans (Table 1). Indeed, only about $5 \%$ of these cases are associated with mutations in the collected toolkit of thyroid-developing genes (mainly PAX8 and TSHR). The reason of this small concordance lies mainly on the fact that the inheritance of the phenotype could be different between humans, mice and zebrafish: patients harboring NKX2-1 ${ }^{+/-}$and/or PAX8 ${ }^{+/-}$develops TD wile mice bearing the same genetic alteration do not show a full-blown hypothyroidism. Indeed, this phenomenon could be explained by the slight difference in human and mouse thyroid morphogenesis during embryogenesis. In fact, the thyroid anlage appears at E8-8.5 and E20-22 in mice and humans, respectively. ${ }^{12}$ Notwithstanding, animal models have been and still are a valuable tool to understand thyroid morpho/dysgenesis.

As both causative mutations have been so far identified in only a small fraction of subjects with TD $(5 \%)^{27}$ and a pattern of Mendelian inheritance can be rarely observed, ${ }^{73}$ it could be stated that monogenic germline mutations possess a marginal role in TD. This hypothesis is reinforced by studies in monozygotic twins that highlighted low 


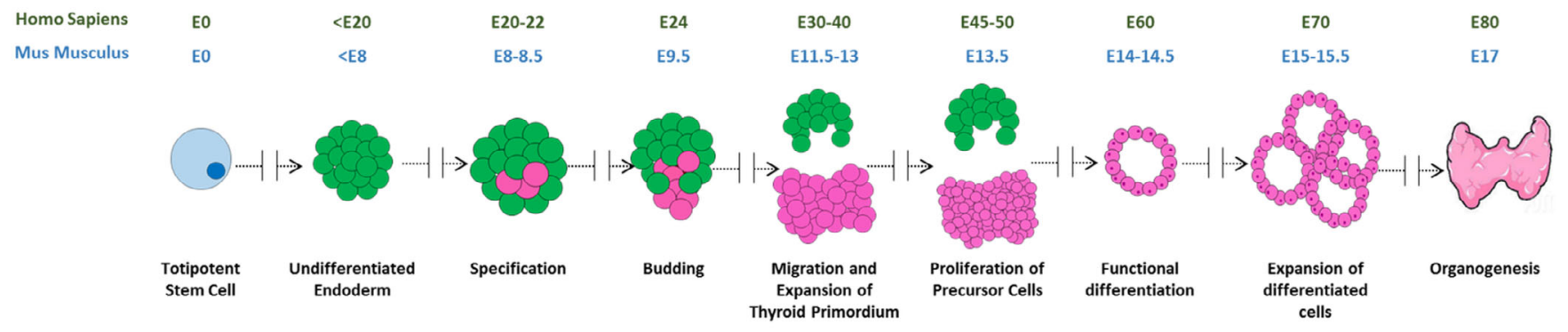

\section{NKX2-1 \\ FOXE1 \\ PAX8 \\ HHEX \\ TSHR}

FIGURE 1 Timing of thyroid gene transcription factors expression during the development of the thyroid gland. Schematic representation of the developmental stages of thyroid genesis and expression of relevant genes. At E8-8.5 in mice and E20-22 in humans, the expression of Nkx2.1, Foxe1, Pax8 and Hhex determine the specification of a group of cells from the ventral endoderm. At about E9.5 and E24 in mice and humans, respectively, the thyroid bud appears as a thickening in the floor of the pharynx. From E11.5 in mice and E30-40 in humans, the thyroid primordium starts its migration from the pharyngeal floor and reaches its definitive pre-tracheal position. Subsequently, the thyroid precursor cells proliferate and expand in a process known as lobulation (E13.5 and E45-50). By E14-14.5 and E60, thyroid follicular cells start to express Tshr during folliculogenesis. At E17 (E80 in humans) the thyroid gland is completely formed. Abbreviations: E, embryonic day; TSHR, thyroidstimulating hormone receptor. Adapted from References ${ }^{20,71,72}$

concordance in TD. In addition, monogenic Mendelian inheritance is difficult to reconcile in thyroid ectopy, because is more prevalent in females. ${ }^{74}$ Therefore, other mechanisms, such as early somatic mutations, epigenetic modifications or stochastic developmental events have been proposed to explain TD. ${ }^{75}$ However, none of these mechanisms has been proved as a major cause of TD. Indeed, it was demonstrated that the methylation profile of ectopic and orthotopic thyroids was highly similar. ${ }^{76}$ Furthermore, a recent study showed no peculiar thyroid ectopy-specific methylation signature after performing a genome-wide DNA methylation analysis. ${ }^{77}$ In addition, somatic mutations were not detected in TD-discordant monozygotic twins by exome sequencing. ${ }^{78}$

Autosomal monoallelic expression (AME) defines unusual autosomal genes with random choice between the maternal and paternal expressed allele. ${ }^{79}$ AME can be classified into two groups: (a) fixed, in which the allele-specific expression of a precursor cell is conserved in descendant cells; and (b) dynamic, which is not transmitted along mitosis and, therefore, can be investigated only at the single cell level. Fixed AME may occur in $10 \%$ to $15 \%$ of autosomal genes. ${ }^{80,81}$ Genes that are expressed in a monoallelic way are more vulnerable to the effect of loss-of-function mutations than the biallelic-expressed genes. Moreover, AME occurs randomly and expands clonally. Whether we apply this phenomenon to genes whose mutation is associated to TD, this would possibly explain the low concordance of TD in monozygotic twins. Indeed, demonstration that AME occurs in thyroid tissue (either normal or ectopic) has been already provided. ${ }^{64}$ In addition to the low concordance between monozygotic twins, this phenomenon could account for the primary sporadic nature of TD. Because of the AME somatic nature, the identification of any TD genetic cause linked to this phenomenon is quite difficult to disclose.
In addition to AME, two other phenomena hinder the identification of genes harboring TD-causing mutations. The first is due to the phenotypic heterogeneity (either inter or intra-familial) of subjects harboring mutation of the same gene. It has been widely shown, for example, that TD due to mutations in $P A X 8^{82}$ $N K X 2-1^{50}$ displayed a variable thyroid phenotype. Furthermore, a second cause could be found in the genetic heterogeneity of this disease.

In conclusion, as recapitulated in the present review, TD can be due to loss-of-function mutations of many different genes. Accordingly, studies in diverse familial cases with TD excluded the involvement of NKX2-1, FOXE1, PAX8 and TSHR genes in the etiology of TD either through linkage or mutational approaches. ${ }^{83}$

Therefore, so far only a small fraction of genes involved in TD have been identified, but the use of NGS approaches is expected to expand the spectrum of TD causative mutations. First, some experimental approaches indicated that other genes could be involved in thyroid development: a conditional knockout mouse for $\mathrm{CDH} 1$, encoding for E-cadherin, demonstrated that the absence of this gene caused smaller and irregularly shaped follicular lumens compared to controls, although no difference in thyroid weight was evaluated. ${ }^{84}$ Therefore, mutations in $\mathrm{CDH} 1$ or in genes involved in its signaling may contribute to TD.

Moreover, a fraction of disease-causing mutations (about 10\%$15 \%$ ) are located in transcriptional cis-regulatory regions (CREs), ${ }^{85}$ not usually investigate by either Sanger or exome sequencing, that is, approaches widely used in TD research. Alterations in thyroid specific-CREs could possibly explain both the low rate in diseasecausing mutation and in the autosomal inheritance highlighted so far. Indeed, Nitsch et al, in 2010, revealed a novel PAX8 enhancer region 
TAB LE 1 Genes directly or indirectly associated with thyroid dysgenesis or syndromic congenital hypothyroidism

\begin{tabular}{|c|c|c|c|c|}
\hline Gene & ID & Expression & Null mice associated phenotype & $\begin{array}{l}\text { Patients loss-of-function } \\
\text { mutation }\end{array}$ \\
\hline HOXA3 & Homeobox protein Hox-A3 & $\begin{array}{l}\text { Neural crest-derived } \\
\text { mesenchymal cells of the } \\
\text { pharyngeal arches; pharyngeal } \\
\text { endoderm }\end{array}$ & Thymus and thyroid hypoplasia & - \\
\hline$N K X 2-1$ & $\begin{array}{l}\text { NK2 Homeobox } 1 / \text { thyroid } \\
\text { transcription factor } 1\end{array}$ & $\begin{array}{l}\text { Thyroid and lung primordia; } \\
\text { central nervous system }\end{array}$ & $\begin{array}{l}\text { Impaired lung morphogenesis; } \\
\text { lack of pituitary gland and } \\
\text { thyroid; severe alterations in } \\
\text { the ventral region of the } \\
\text { forebrain }\end{array}$ & $\begin{array}{l}\text { Thyroid hypoplasia, } \\
\text { haemiagenesis or athyreosis; } \\
\text { respiratory distress syndrome; } \\
\text { benign hereditary chorea } \\
\text { (brain-lung-thyroid syndrome) }\end{array}$ \\
\hline PAX8 & Paired box 8 & $\begin{array}{l}\text { Thyroid and kidney primordia } \\
\text { and midbrain-hindbrain } \\
\text { boundary }\end{array}$ & $\begin{array}{l}\text { Small thyroid gland with absence } \\
\text { of follicles; disappearance of } \\
\text { the thyroid precursor cells at } \\
\text { E12.5 }\end{array}$ & $\begin{array}{c}\text { Thyroid hypoplasia; rarely } \\
\text { ectopy and athyreosis }\end{array}$ \\
\hline FOXE1 & $\begin{array}{l}\text { Forkhead box protein } \\
\text { E1/thyroid transcription } \\
\text { factor } 2\end{array}$ & $\begin{array}{l}\text { Developing thyroid, foregut } \\
\text { endoderm; pituitary gland } \\
\text { primordia }\end{array}$ & $\begin{array}{l}\text { Cleft palate; absence of the } \\
\text { thyroid gland and thyroid } \\
\text { hormones }\end{array}$ & $\begin{array}{l}\text { Thyroid dysgenesis; cleft palate; } \\
\text { spiky hair (Bamforth-Lazarus } \\
\text { syndrome) }\end{array}$ \\
\hline HHEX & $\begin{array}{l}\text { Hematopoietically } \\
\text { expressed homeobox }\end{array}$ & $\begin{array}{l}\text { Primitive endoderm; ventral gut; } \\
\text { thyroid, liver, thymus, } \\
\text { pancreas and lungs primordia }\end{array}$ & $\begin{array}{l}\text { Thyroid hypoplasia and ectopy } \\
\text { at E9.5 }\end{array}$ & - \\
\hline HES1 & $\begin{array}{l}\text { Hes family BHLH } \\
\text { Transcription Factor } 1\end{array}$ & Neural crest mesenchyme & $\begin{array}{l}\text { Neural hypoplasia; severe } \\
\text { thyroid hypoplasia; absence of } \\
\text { C cells; cleft palate; }\end{array}$ & - \\
\hline EYA1 & $\begin{array}{l}\text { EYA transcriptional } \\
\text { coactivator and } \\
\text { phosphatase } 1\end{array}$ & $\begin{array}{l}\text { Pharyngeal arches' mesenchyme; } \\
\text { pouches' endoderm; surface } \\
\text { ectoderm of the clefts; } \\
\text { thymus, parathyroid, and } \\
\text { ultimobranchial bodies }\end{array}$ & $\begin{array}{l}\text { Hypoplasia of thyroid lobes; } \\
\text { absence of the isthmus; } \\
\text { reduced number of follicular } \\
\text { cells }\end{array}$ & - \\
\hline TSHR & $\begin{array}{l}\text { Thyroid stimulating } \\
\text { hormone receptor }\end{array}$ & $\begin{array}{l}\text { Thyroid follicular organization in } \\
\text { the developed gland }\end{array}$ & $\begin{array}{l}\text { Severe hypothyroidism; thyroid } \\
\text { hypoplasia }\end{array}$ & Hyperthyrotropinaemia \\
\hline TUBB1 & $\begin{array}{l}\text { Tubulin beta } 1 \\
\text { Class VI }\end{array}$ & $\begin{array}{l}\text { Thyroid primordia; } \\
\text { megakaryocytes and platelets }\end{array}$ & $\begin{array}{l}\text { Bigger thyroid anlage at E9.5 } \\
\text { followed by thyroid } \\
\text { hypoplasia at E13.5 }\end{array}$ & $\begin{array}{l}\text { Thyroid gland ectopia or mild } \\
\text { thyroid asymmetry or thyroid } \\
\text { hypoplasia or hemithyroid; } \\
\text { macroplatelets }\end{array}$ \\
\hline GLIS3 & GLIS family zinc finger 3 & Early embryo & $\begin{array}{l}\text { Reduced thyroid cell } \\
\text { proliferation }\end{array}$ & $\begin{array}{l}\text { Thyroid aplasia; diminished } \\
\text { colloid with interstitial fibrosis; } \\
\text { TSH resistance }\end{array}$ \\
\hline JAG1 & $\begin{array}{l}\text { Jagged Canonical Notch } \\
\text { Ligand } 1\end{array}$ & $\begin{array}{l}\text { Thyroid specification, } \\
\text { differentiation and } \\
\text { maintenance of thyroid } \\
\text { precursor cells }\end{array}$ & - & $\begin{array}{l}\text { Thyroid hypoplasia; liver, heart, } \\
\text { skeleton, eye and facial } \\
\text { defects (Alagille syndrome } \\
\text { type 1) }\end{array}$ \\
\hline$N K X 2-5$ & NK2 Homeobox 5 & $\begin{array}{l}\text { Ventral side of the pharynx; } \\
\text { thyroid anlage }\end{array}$ & Thyroid bud hypoplasia & Thyroid ectopy or athyreosis \\
\hline NTN1 & Netrin 1 & Pharyngeal arch mesenchyme & - & $\begin{array}{l}\text { Congenital ventricular septum } \\
\text { defect; Thyroid ectopy }\end{array}$ \\
\hline CDCA8 & $\begin{array}{l}\text { Cell division cycle associated } \\
8\end{array}$ & Cell migration and adhesion & Thyroid ectopy & Thyroid ectopy \\
\hline
\end{tabular}

regulated by $N K X 2-1$, suggesting that any alteration in this loop could predispose to TD. ${ }^{70}$

Finally, as demonstrated by using multitarget-knockout mice, TD can rise as a polygenic disease. ${ }^{46}$ Because of the wide phenotypic variation of either thyroid hypoplasia or ectopy, it is conceivable to think that these abnormalities could be determined by variation of quantitative traits, that is, thyroid cells growth and migration, respectively, as a result of polygenic effects. Targeted NGS studies in TD patients' cohorts highlighted that heritable mutations accounts for at least $50 \%$ of patients. ${ }^{86}$ Moreover, according to what was revealed using mouse models, ${ }^{46}$ a significant proportion of patients have multiple gene variations in more than one thyroid specific gene. Importantly, some TD candidate gene variations highlighted so far can be assessed also in the general population with a significantly lower prevalence, ${ }^{15}$ thus, 
indicating that the of pathogenesis of TD can be due to the sum of multiple rare alleles that act in concert to generate the pathological phenotype. In this context, the extensive use of exome and whole genome sequencing that characterize the nowadays genetic approach to pathological conditions could definitively shed light on the genetic causes underlying polygenic diseases. Thus, whether these approaches will be applied to TD, they are expected to aid in identifying the unknown molecular features at the bottom of this disease.

\section{CONFLICT OF INTEREST}

The authors have no conflicts of interest to declare.

\section{DATA ACCESSIBILITY}

Data sharing is not applicable to this article as no new data were created or analyzed in this study.

\section{ORCID}

Catia Mio (iD) https://orcid.org/0000-0002-6245-8266

Giorgio Grani (D) https://orcid.org/0000-0002-0388-1283

\section{REFERENCES}

1. Fagman H, Nilsson M. Morphogenesis of the thyroid gland. Mol Cell Endocrinol. 2010;323:35-54.

2. Kempers MJE, Ozgen HM, Vulsma T, et al. Morphological abnormalities in children with thyroidal congenital hypothyroidism. Am J Med Genet A. 2009;149A:943-951.

3. Klein AH, Meltzer S, Kenny FM. Improved prognosis in congenital bypothyroidism treated before age three months. J Pediatr. 1972;81: 912-915.

4. Morreale de Escobar G. The role of thyroid hormone in fetal neurodevelopment. J Pediatr Endocrinol Metab. 2001;14(Suppl 6):14531462.

5. Grasberger H, Refetoff S. Genetic causes of congenital hypothyroidism due to dyshormonogenesis. Curr Opin Pediatr. 2011;23:421-428.

6. Deladoëy J, Bélanger N, Van Vliet $\mathrm{G}$. Random variability in congenital hypothyroidism from thyroid dysgenesis over 16 years in Québec. J Clin Endocrinol Metab. 2007;92:3158-3161.

7. Abramowicz MJ, Duprez L, Parma J, Vassart G, Heinrichs C. Familial congenital hypothyroidism due to inactivating mutation of the thyrotropin receptor causing profound hypoplasia of the thyroid gland. J Clin Invest. 1997;99:3018-3024.

8. Léger J, Marinovic D, Garel C, Bonaïti-Pellié C, Polak M, Czernichow P. Thyroid developmental anomalies in first degree relatives of children with congenital hypothyroidism. J Clin Endocrinol Metab. 2002;87:575-580.

9. Nilsson M, Fagman H. Development of the thyroid gland. Development. 2017;144(12):2123-2140. https.//doi.org./10.1242/dev.145615

10. McLean R, Howard N, Murray IPC. Thyroid dysgenesis in monozygotic twins: variants identified by scintigraphy. Eur J Nucl Med. 1985; 10:346-348.

11. De Felice M, Ovitt C, Biffali E, et al. A mouse model for hereditary thyroid dysgenesis and cleft palate. Nat Genet. 1998;19:395-398.

12. De Felice M, Di Lauro R. Thyroid development and its disorders: genetics and molecular mechanisms. Endocr Rev. 2004;25:722-746.
13. Perry R, Heinrichs C, Bourdoux P, et al. Discordance of monozygotic twins for thyroid dysgenesis: implications for screening and for molecular pathophysiology. J Clin Endocrinol Metab. 2002;87:40724077.

14. van Vliet G, Vassart G. Monozygotic twins are generally discordant for congenital hypothyroidism from thyroid dysgenesis. Horm Res. 2009;72:320-320.

15. Persani L, Rurale G, de Filippis T, Galazzi E, Muzza M, Fugazzola L. Genetics and management of congenital hypothyroidism. Best Pract Res Clin Endocrinol Metab. 2018;32:387-396.

16. Manley NR, Capecchi MR. The role of Hoxa-3 in mouse thymus and thyroid development. Development. 1995;121:1989-2003.

17. Guazzi S, Price M, De Felice M, Damante G, Mattei MG, Di Lauro R. Thyroid nuclear factor 1 (TTF-1) contains a homeodomain and displays a novel DNA binding specificity. EMBO J. 1990;9:3631-3639.

18. Damante G, Pellizzari L, Esposito G, et al. A molecular code dictates sequence-specific DNA recognition by homeodomains. EMBO J. 1996;15:4992-5000.

19. Damante G, Tell G, Di Lauro R. A unique combination of transcription factors controls differentiation of thyroid cells. Prog Nucleic Acid Res Mol Biol. 2001;66:307-356.

20. Fernández LP, López-Márquez A, Santisteban P. Thyroid transcription factors in development, differentiation and disease. Nat Rev Endocrinol. 2015;11:29-42.

21. Szinnai G. Genetics of normal and abnormal thyroid development in humans. Best Pract Res Clin Endocrinol Metab. 2014;28:133-150.

22. Price M, Lazzaro D, Pohl T, et al. Regional expression of the homeobox gene Nkx-2.2 in the developing mammalian forebrain. Neuron. 1992;8:241-255.

23. Kimura S, Hara Y, Pineau T, et al. The T/ebp null mouse: thyroidspecific enhancer-binding protein is essential for the organogenesis of the thyroid, lung, ventral forebrain, and pituitary. Genes Dev. 1996; 10:60-69.

24. Strachan T, Read AP. PAX genes. Curr Opin Genet Dev. 1994;4: 427-438.

25. Mansouri A, Hallonet M, Gruss P. Pax genes and their roles in cell differentiation and development. Curr Opin Cell Biol. 1996;8:851-857.

26. Mansouri A, Chowdhury K, Gruss P. Follicular cells of the thyroid gland require Pax8 gene function. Nat Genet. 1998;19:87-90.

27. Peters C, van Trotsenburg ASP, Schoenmakers N. DIAGNOSIS OF ENDOCRINE DISEASE: congenital hypothyroidism: update and perspectives. Eur J Endocrinol. 2018;179:R297-R317.

28. Zannini M, Avantaggiato $\mathrm{V}$, Biffali E, et al. TTF-2, a new forkhead protein, shows a temporal expression in the developing thyroid which is consistent with a role in controlling the onset of differentiation. EMBO J. 1997;16:3185-3197.

29. Pellizzari L, D'Elia A, Rustighi A, Manfioletti G, Tell G, Damante G. Expression and function of the homeodomain-containing protein hex in thyroid cells. Nucleic Acids Res. 2000;28:2503-2511.

30. Thomas PQ, Brown A, Beddington RS. Hex: a homeobox gene revealing peri-implantation asymmetry in the mouse embryo and an early transient marker of endothelial cell precursors. Development. 1998; 125:85-94.

31. Puppin C, Presta I, D'Elia AV, et al. Functional interaction among thyroid-specific transcription factors: Pax8 regulates the activity of hex promoter. Mol Cell Endocrinol. 2004;214:117-125.

32. Puppin C, D'Elia AV, Pellizzari L, et al. Thyroid-specific transcription factors control hex promoter activity. Nucleic Acids Res. 2003;31: 1845-1852.

33. Barbera JPM, Clements M, Thomas P, et al. The homeobox gene hex is required in definitive endodermal tissues for normal forebrain, liver and thyroid formation. Development. 2000;127:2433-2445.

34. Parlato R, Rosica A, Rodriguez-Mallon A, et al. An integrated regulatory network controlling survival and migration in thyroid organogenesis. Dev Biol. 2004;276:464-475. 
35. Ferretti E, Tosi E, Po A, et al. Notch signaling is involved in expression of Thyrocyte differentiation markers and is Down-regulated in thyroid tumors. J Clin Endocrinol Metab. 2008;93:4080-4087.

36. Carre A, Rachdi L, Tron E, et al. Hes1 is required for appropriate morphogenesis and differentiation during mouse thyroid gland development. PLoS One. 2011;6:e16752.

37. Kageyama R, Ohtsuka T, Tomita and K. The bHLH gene Hes1 regulates differentiation of multiple cell types. Mol Cells. 2000;10:1-7.

38. Kageyama R, Ohtsuka T. The Notch-Hes pathway in mammalian neural development. Cell Res. 1999;9:179-188.

39. Porazzi P, Marelli F, Benato F, et al. Disruptions of global and Jagged1-mediated Notch signaling affect thyroid morphogenesis in the zebrafish. Endocrinology. 2012;153:5645-5658.

40. Xu HE, Rould MA, Xu W, Epstein JA, Maas RL, Pabo CO. Crystal structure of the human Pax6 paired domain-DNA complex reveals specific roles for the linker region and carboxy-terminal subdomain in DNA binding. Genes Dev. 1999;13:1263-1275.

41. Xu P-X, Zheng W, Laclef C, et al. Eya1 is required for the morphogenesis of mammalian thymus, parathyroid and thyroid. Development. 2002;129:3033-3044.

42. Marians RC, Ng L, Blair HC, Unger P, Graves PN, Davies TF. Defining thyrotropin-dependent and-independent steps of thyroid hormone synthesis by using thyrotropin receptor-null mice. Proc Natl Acad Sci U S A. 2002;99:15776-15781.

43. Postiglione MP, Parlato R, Rodriguez-Mallon A, et al. Role of the thyroid-stimulating hormone receptor signaling in development and differentiation of the thyroid gland. Proc Natl Acad Sci U S A. 2002; 99:15462-15467.

44. Yang J, Yi N, Zhang J, et al. Generation and characterization of a hypothyroidism rat model with truncated thyroid stimulating hormone receptor. Sci Rep. 2018;8(1):4004.

45. Stoupa A, Adam F, Kariyawasam D, et al. TUBB1 mutations cause thyroid dysgenesis associated with abnormal platelet physiology. EMBO Mol Med. 2018;10(12):e9569.

46. Amendola E, De Luca P, Macchia PE, et al. A mouse model demonstrates a multigenic origin of congenital hypothyroidism. Endocrinology. 2005;146:5038-5047.

47. Amendola E, Sanges R, Galvan A, et al. A locus on mouse chromosome 2 is involved in susceptibility to congenital hypothyroidism and contains an essential gene expressed in thyroid. Endocrinology. 2010; 151:1948-1958.

48. de Filippis T, Marelli F, Vigone MC, Di Frenna M, Weber G, Persani L. Novel NKX2-1 frameshift mutations in patients with atypical phenotypes of the brain-lung-thyroid syndrome. Eur Thyroid J. 2014;3:227-233.

49. Thorwarth A, Schnittert-Hübener S, Schrumpf $P$, et al. Comprehensive genotyping and clinical characterisation reveal 27 novel NKX2-1 mutations and expand the phenotypic spectrum. J Med Genet. 2014; 51:375-387.

50. Makretskaya N, Bezlepkina O, Kolodkina A, et al. High frequency of mutations in "dyshormonogenesis genes" in severe congenital hypothyroidism. PLoS One. 2018;13(9):e0204323.

51. Abu-Khudir R, Larrivée-Vanier S, Wasserman JD, Deladoëy J. Disorders of thyroid morphogenesis. Best Pract Res Clin Endocrinol Metab. 2017;31:143-159.

52. Macchia PE, Lapi $P$, Krude $H$, et al. PAX8 mutations associated with congenital hypothyroidism caused by thyroid dysgenesis. Nat Genet. 1998;19:83-86.

53. Carré $A$, Castanet $M$, Sura-Trueba $S$, et al. Polymorphic length of FOXE1 alanine stretch: evidence for genetic susceptibility to thyroid dysgenesis. Hum Genet. 2007;122:467-476.

54. Persani L, Calebiro D, Cordella D, et al. Genetics and phenomics of hypothyroidism due to TSH resistance. Mol Cell Endocrinol. 2010;322: 72-82.

55. Cassio A, Nicoletti A, Rizzello A, Zazzetta E, Bal M, Baldazzi L. Current loss-of-function mutations in the thyrotropin receptor gene: when to investigate, clinical effects, and treatment. I Clin Res Pediatr Endocrinol. 2013;5:29-39.

56. Grasberger H, Refetoff S. Resistance to thyrotropin. Best Pract Res Clin Endocrinol Metab. 2017;31:183-194.

57. Dimitri P. The role of GLIS3 in thyroid disease as part of a multisystem disorder. Best Pract Res Clin Endocrinol Metab. 2017;31: 175-182.

58. Marelli F, Persani L. Role of Jagged1-Notch pathway in thyroid development. J Endocrinol Invest. 2018;41:75-81.

59. de Filippis T, Marelli F, Nebbia G, et al. JAG1 loss-of-function variations as a novel predisposing event in the pathogenesis of congenital thyroid defects. J Clin Endocrinol Metab. 2016;101:861-870.

60. Carré A, Stoupa A, Kariyawasam D, et al. Mutations in BOREALIN cause thyroid dysgenesis. Hum Mol Genet. 2017;26:599-610.

61. Dentice M, Cordeddu V, Rosica A, et al. Missense mutation in the transcription factor NKX2-5: a novel molecular event in the pathogenesis of thyroid dysgenesis. J Clin Endocrinol Metab. 2006;91:14281433.

62. Opitz R, Hitz M-P, Vandernoot I, et al. Functional zebrafish studies based on human genotyping point to Netrin-1 as a link between aberrant cardiovascular development and thyroid dysgenesis. Endocrinology. 2015;156:377-388.

63. Eckersley-Maslin MA, Thybert D, Bergmann JH, Marioni JC, Flicek P, Spector DL. Random Monoallelic gene expression increases upon embryonic stem cell differentiation. Dev Cell. 2014;28:351-365.

64. Magne F, Ge B, Larrivée-Vanier S, et al. Demonstration of autosomal Monoallelic expression in thyroid tissue assessed by whole-exome and bulk RNA sequencing. Thyroid. 2016;26:852-859.

65. Zhou Z, Yang C, Lv F, et al. Novel THRB mutation analysis in congenital hypothyroidism with thyroid dysgenesis. J Cell Biochem. 2018;119: 9474-9482.

66. Nakajima Y, Yamada M, Horiguchi K, et al. Resistance to thyroid hormone due to a novel thyroid hormone receptor mutant in a patient with hypothyroidism secondary to lingual thyroid and functional characterization of the mutant receptor. Thyroid. 2010;20:917-926.

67. Cherella CE, Wassner AJ. Congenital hypothyroidism: insights into pathogenesis and treatment. Int J Pediatr Endocrinol. 2017;2017:11.

68. Mantovani G, Elli FM, Corbetta S. Hypothyroidism associated with parathyroid disorders. Best Pract Res Clin Endocrinol Metab. 2017;31: 161-173.

69. Bongsebandhu-phubhakdi C, Tempark T, Supornsilpchai V. Endocrine manifestations of PHACE syndrome. J Pediatr Endocrinol Metabo. 2019;32:797-802.

70. Nitsch R, Di Dato V, di Gennaro A, et al. Comparative genomics reveals a functional thyroid-specific element in the far upstream region of the PAX8 gene. BMC Genomics. 2010;11:306.

71. Davies TF, Latif R, Minsky NC, Ma R. The emerging cell biology of thyroid stem cells. J Clin Endocrinol Metabol. 2011;96:2692-2702.

72. Löf C, Patyra K, Kero A, Kero J. Genetically modified mouse models to investigate thyroid development, function and growth. Best Pract Res Clin Endocrinol Metab. 2018;32:241-256.

73. Castanet $\mathrm{M}$, Lyonnet $\mathrm{S}$, Bonaïti-Pellié $\mathrm{C}$, Polak $\mathrm{M}$, Czernichow $\mathrm{P}$, Léger J. Familial forms of thyroid dysgenesis among infants with congenital hypothyroidism. N Eng J Med. 2000;343:441-442.

74. Devos H, Rodd C, Gagné N, Laframboise R, Van Vliet G. A search for the possible molecular mechanisms of thyroid dysgenesis: sex ratios and associated malformations. J Clin Endocrinol Metab. 1999;84:2502-2506.

75. Vliet GV. Development of the thyroid gland: lessons from congenitally hypothyroid mice and men. Clin Genet. 2003;63:445-455.

76. Abu-Khudir R, Paquette J, Lefort A, et al. Transcriptome, Methylome and genomic variations analysis of ectopic thyroid glands. PLoS One. 2010;5(10):e13420.

77. Narumi S, Matsubara K, Ishii T, Hasegawa T. Methylome analysis of thyroid ectopy shows no disease-specific DNA methylation signature. Clin Pediatr Endocrinol. 2018:27:235-238. 
78. Magne F, Serpa R, Van Vliet G, Samuels ME, Deladoëy J. Somatic mutations are not observed by exome sequencing of lymphocyte DNA from monozygotic twins discordant for congenital hypothyroidism due to thyroid dysgenesis. Horm Res Paediatr. 2015;83:79-85.

79. Gimelbrant A, Hutchinson JN, Thompson BR, Chess A. Widespread Monoallelic expression on human autosomes. Science. 2007;318: 1136-1140.

80. Zwemer LM, Zak A, Thompson BR, et al. Autosomal monoallelic expression in the mouse. Genome Biol. 2012;13:R10.

81. Savova V, Vigneau S, Gimelbrant AA. Autosomal monoallelic expression: genetics of epigenetic diversity? Curr Opin Genet Dev. 2013;23: 642-648.

82. Ramos HE, Carré A, Chevrier L, et al. Extreme phenotypic variability of thyroid dysgenesis in six new cases of congenital hypothyroidism due to PAX8 gene loss-of-function mutations. Eur J Endocrinol. 2014; 171:499-507.

83. Castanet $M$, Sura-Trueba $S$, Chauty $A$, et al. Polak $M$ linkage and mutational analysis of familial thyroid dysgenesis demonstrate genetic heterogeneity implicating novel genes. European J Hum Genet. 2005; 13:232.

84. Cali G, Zannini M, Rubini $P$, et al. Conditional inactivation of the $E-$ cadherin gene in thyroid follicular cells affects gland development but does not impair junction formation. Endocrinology. 2007;148:2737-2746.

85. Mathelier A, Shi W, Wasserman WW. Identification of altered cisregulatory elements in human disease. Trends Genet. 2015;31:67-76.

86. de Filippis T, Gelmini G, Paraboschi E, et al. A frequent oligogenic involvement in congenital hypothyroidism. Hum Mol Genet. 2017;26: 2507-2514.

How to cite this article: Mio C, Grani G, Durante C, Damante G. Molecular defects in thyroid dysgenesis. Clin Genet. 2020;97:222-231. https://doi.org/10.1111/cge.13627 